\title{
A ESTÉTICA COMO PERSPECTIVA DE ENSINO NA EDUCAÇÃO FÍSICA ESCOLAR: UM DIÁLOGO COM ALUNOS DO ENSINO MÉDIO
}

Rayane Monaliza da Nóbrega Oliveira, Universidade Federal do Rio Grande do Norte - UFRGN, Natal, Rio Grande do Norte-Brasil

Rose Marie Nascimento de Medeiros, Universidade Federal do Rio Grande do NorteUFRGN, Natal, Rio Grande do Norte - Brasil

\section{RESUMO}

Este artigo é parte de uma monografia que refletiu sobre a estética no âmbito escolar da Educação Física. Trata-se de uma pesquisa qualitativa descritiva que utiliza o questionário como instrumento para analisar as compreensões de beleza de alunos do ensino médio das escolas: Cooperativa de Parelhas $(\mathrm{RN})$ e do Colégio Impacto (Natal, $\mathrm{RN})$. Os dados apontam, principalmente, para questões relacionadas à aparência de um corpo belo, padronizado e difundido na sociedade. Visualizamos nas aulas de Educação Física, um espaço para ampliar e aprofundar as discussões sobre estética, considerando as experiências vividas dos alunos.

Palavras-Chave: Estética; Adolescentes; Educação física.

\section{A ESTHETICS AS A TEACHING PERSPECTIVE IN PHYSICAL EDUCATION: A DIALOGUE WITH HIGH SCHOOL STUDENTS}

\begin{abstract}
This article is part of a paper that discussed the aesthetic in the school of Physical Education. It is a descriptive qualitative study using the questionnaire as a tool to analyze the understandings of beauty school students from schools: Cooperativa de Parelhas (RN) and Colégio Impacto (Natal, RN). The data points, mainly on issues related to the appearance of a beautiful body, standardized and widespread in society. Visualized in physical education classes, a space to broaden and deepen discussions on aesthetics, considering the subjectivity of the subject.
\end{abstract}

Key-Words: Aesthetics; Adolescents; Physical education.

\section{ESTÉTICA COMO UNA PERSPECTIVA DE LA ENSEÑANZA EN EDUCACIÓN FÍSICA: UN DIÁLOGO CON LOS ESTUDIANTES DE EDUCACIÓN SECUNDARIA}

\section{RESUMEN}

Este artículo es parte de una monografía que se refleja en la estética en el contexto de la escuela de educación física. Es una investigación cualitativa descriptiva que utiliza el cuestionario como un instrumento para analizar los entendimientos de la belleza de los estudiantes de secundaria de las escuelas: Cooperativa de Parelhas (RN) y el Colégio Impacto (Natal, RN). El punto de datos, principalmente, a cuestiones relacionadas con la aparición de un cuerpo hermoso, estandarizada y difundido en la sociedad. 
Visualizamos en clases de educación física, un espacio para ampliar y profundizar los debates sobre estética, teniendo en cuenta las experiencias de los estudiantes.

Palabras-Clave: Estética; Adolescentes; Educación física. 


\section{INTRODUÇÃO}

Este artigo é parte constituinte de uma monografia intitulada "Estética, mídia e educação física escolar: reflexões sobre os discursos dos alunos do ensino médio"; orientada pela Prof. ${ }^{a}$ Rosie Marie e apresentada ao curso de Educação Física na Universidade Federal do Rio Grande do Norte, no ano de 2010. Na ocasião, discutimos as compreensões de beleza dos alunos do Ensino Médio e o poder da mídia na influência da idealização de um corpo belo, apontando para a Educação Física escolar como um espaço estratégico para ampliarmos e aprofundarmos as discussões sobre a estética, considerando a subjetividade dos sujeitos. Para tanto, aplicamos questionários aos adolescentes entre 15 e 17 anos, sendo o primeiro grupo formado por 10 alunos (de ambos os sexos) do ensino médio da Escola Cooperativa Educacional de Parelhas, Parelhas - RN; e o segundo grupo constituído por 10 alunos (de ambos os sexos), do mesmo nível de ensino, do Impacto Colégio e Curso, Natal - RN. As respostas dos adolescentes foram exploradas a partir da literatura que versa sobre os conceitos de beleza e estética com o propósito de problematizá-los no âmbito da Educação Física escolar.

Neste momento enfocamos, particularmente, os discursos sobre as compreensões de beleza que nos permitiram direcionar novos olhares para o campo da estética e valorizála no trato pedagógico da Educação Física. Parece-nos fundamental uma discussão nessa área que envolva as questões éticas e estéticas do corpo para que nossos alunos sejam capazes de analisar criticamente os padrões e, finalmente, refletirem sobre que corpo desejam ter e para quê. Nessa ordem de ideias, iniciamos situando, brevemente, o tema sugerido, explorando alguns conceitos que fundamentem nossas discussões. Em seguida, apresentamos e discutimos as diferentes compreensões de beleza para, então, apontar perspectivas para o processo de ensino/aprendizagem.

\section{SITUANDO A TEMÁTICA}

A Educação Física é uma área do conhecimento que abrange o universo das práticas corporais. Destarte, é inegável sua estreita relação com o corpo e seus entrelaces com a beleza. Entre seus diversos campos de intervenção, a escola desponta com sua importância, apresentando-se como instrumento de ensino e aprendizagem no qual o corpo aparece como foco dando base de sustentação para as aulas, prioritariamente 
práticas, adentrando para seus conteúdos: esportes, jogos, lutas, ginástica, atividades rítmicas e expressivas, e conhecimentos sobre o corpo; como estão explícitos nos Parâmetros Curriculares Nacionais. ${ }^{1}$

De acordo com Nóbrega: ${ }^{2: 83}$

\begin{abstract}
A Educação Física, ao intervir sobre o corpo e o movimento, deve estar atenta para os aspectos da saúde, do bem-estar, do desenvolvimento das capacidades orgânicas, mas deve ampliar o seu campo de referência para a questão ética e estética do movimento, a beleza e harmonia dos gestos, possibilitando ampliar a percepção de si mesmo, do outro e do mundo, contribuindo para o redimensionamento do ser humano e da vida no planeta, tendo como referência básica a corporeidade.
\end{abstract}

No âmbito da Educação física escolar, observamos o aumento das inúmeras referências ao corpo humano, muitas vezes sendo percebido em seu aparato biológico, outras vezes considerando aspectos sociais em suas definições, e, sobretudo, sendo relacionado a padrões estéticos ou à beleza. Nesse contexto, o termo "estética" surge, frequentemente, e de forma não criteriosa, relacionado a um "corpo belo" padronizado e aos gestos técnicos realizados nas práticas corporais.

Concordando com Porpino, ${ }^{3}$ o fato de a estética estar historicamente ligada à Arte, talvez leve ao entendimento de que aquela tenha pouca ou nenhuma relação com a Educação Física, área do conhecimento na qual ainda predominam as referências conceituais das Ciências Naturais. Todavia, sabe-se que essa ligação com a arte delimita o campo estético, o que se faz necessário ampliar o termo Estética, onde se encontra presente na contemporaneidade.

Inicialmente, há de se considerar o que compreendemos por beleza ou belo. Nesse sentido, fazemos referência à Grécia Antiga onde impera um ideal de beleza que traz o Apolo como figura emblemática: o deus da simetria, da ordem, da medida e do equilíbrio; representante de uma beleza aparente capaz de camuflar a verdadeira realidade e incitar o prazer e a força necessária à existência. ${ }^{3}$ E hoje? Tudo mudou? Não precisamos nem pensar muito para dar um "NÃO" como resposta.

$\mathrm{Na}$ contemporaneidade ainda nos deparamos com esse ideal que detém o poder de impulsionar às pessoas, muitas vezes, a se submeterem aos "sacrifícios" das restrições alimentares, dos exercícios extenuantes, dos modismos, bem como, das cirurgias plásticas estéticas. Como retrata Parisoli: ${ }^{4: 35}$

Conexões: revista da Faculdade de Educação Física da UNICAMP, Campinas, v. 12, n. 3, p. 1-17, jul./set. 2014. 
O ideal contemporâneo é o ideal de um corpo completamente enxuto, compacto, firme, jovem e musculoso: um corpo protegido dos sinais do tempo e no qual os processos internos são controlados pelos regimes alimentares, pelo exercício físico e pela cirurgia estética [...]. Portanto, o corpo é um objeto a construir segundo a moda, como o revelador de nossa personalidade, como a imagem que os outros encontram e escolhem.

Todo esse contexto traz algumas consequências insatisfatórias, incluindo o modo de participação e os objetivos dos alunos nas aulas de Educação Física, gerando uma preocupação maior na construção do processo ensino-aprendizagem, que deve contemplar temas diversos abrangendo essas questões que dominam a cultura e o "modismo" da população, em geral.

É mister ressaltar que esse belo apolíneo é apenas uma das categorias da estética, ao lado de outras como o trágico, o cômico ou o feio, e não como delimitação do campo estético. De acordo com Dufrenne apud Porpino ${ }^{3}$ é possível descrever o belo a partir da percepção:

É a qualidade presente em certos objetos - sempre singulares - que nos são dados à percepção do ser percebido (mesmo se essa percepção requer longa aprendizagem e longa familiaridade com o objeto). Perfeição do sensível antes de tudo, que se impõe com uma espécie de necessidade e logo desencoraja qualquer ideia de retoque. Mas é também imanência total de um sentido ao sensível, sem o que o objeto seria insignificante: agradável, decorativo ou deleitável quando muito. ${ }^{3: 86}$

Dessa forma, podemos desmistificar o conhecimento do senso comum que trata a estética restrita aos corpos físicos. Além disso, observamos que não se trata de considerar o belo apenas pelo enobrecimento do sentindo da visão, mas, sobretudo, compreendê-lo como um ato de reciprocidade entre o que se percebe e o que é percebido.

Nesse sentindo, Porpino ${ }^{3: 87}$ argumenta:

Esse conceito de beleza nos faz perceber o cerne da experiência estética como a vivência do sensível, considerando esta como um entrelaçamento entre aquele que sente e objeto sentido, capaz de formar uma espacialidade única, uma espacialidade que não está fora do corpo, mas que é o próprio corpo imerso na reversibilidade com o mundo no ato de interpretar interpretando-se.

Nessa ordem de ideias, convocamos a subjetividade para ser protagonista das nossas reflexões; agora parece claro: cada indivíduo tem uma experiência e relação própria, como observador que mantém uma relação de reciprocidade com o que está sendo 
observado. Ademais, tomamos como exemplo a frase dita corriqueiramente "beleza está nos olhos de quem vê". Talvez seja proferida de maneira indiscriminada, mas carrega um significado que contempla a compreensão acerca do belo.

Em contrapartida, Tolledo ${ }^{5: 88}$ nos apresenta outra categoria do conceito de belo representada pelo Deus grego Dionisio:

\begin{abstract}
Este ultrapassa o mundo do sofrimento pelo mergulho à unidade do próprio universo, uma experiência mística, levando ao inconsciente. Dionísio é o deus do vinho que se liga a musica e à arte não - configurada. A experiência dionisíaca é a perda de si mesmo, de sua individualização, e essa ideia de perda de si nos remete à de terror. Essa experiência vai selar o laço que une pessoa a pessoa, eliminando todas as diferentes individualizações.
\end{abstract}

Mediante tais ponderações sobre a beleza, podemos retomar a estética, ou melhor, como relata Porpino, ${ }^{3}$ a experiência estética, vista como uma eminência corporal, que se manifesta e toma sentido no corpo, na identificação recíproca com os objetos, com os outros seres humanos e com a natureza da qual o próprio homem é constituído e constituinte.

Diante dessas discussões Porpino ${ }^{6: 157}$ relata:

Viver a experiência estética como possibilidade de criação de múltiplas interpretações mostra-nos uma perspectiva de ensino capaz de propiciar a retomada contínua da plasticidade corpórea. O corpo, como já mostrava Merleau-Ponty (1994), não é uma ideia de corpo nem tampouco uma associação de órgãos justapostos, mas um campo aberto a infinitas possibilidades do conhecer. Somos o nosso corpo e só podemos compreendêlo vivendo-o e nos confundindo com ele.

Assim, as aulas de Educação Física devem contemplar experiências corporais, com criações e re-significações das práticas já existentes; é imprescindível oferecer um processo contínuo e flexível que atenda às exigências do momento vivenciado. Os diferentes questionamentos sobre corpo surgidos pelos próprios alunos servem como subsídios para que o professor trabalhe esse corpo dentro de uma perspectiva que transcenda a concepção de máquina que pode ser manipulável de acordo com o aparato do Universo do fitness, por exemplo.

\title{
3 REFLEXÕES SOBRE AS CONCEPÇÕES DE BELEZA
}

De acordo com Porpino, ${ }^{3}$ na época em que vivemos apontar para a estética nos remete a múltiplas compreensões e significados. Palavras como o belo, a sensibilidade, a arte, o 
prazer, são tidas, frequentemente, como sinônimos nesse universo da estética. No nosso estudo, foi enfatizada a partir da experiência da beleza como uma de suas categorias, mas "não como delimitação do campo estético, visto que dessa forma estaríamos negando a dimensão estética de algumas produções culturais [...]”. 3:83

Diante de tantas interpretações e perspectivas acerca da beleza, apontaremos para um olhar voltado às concepções dos alunos do Ensino Médio, nível de ensino que pode ser caracterizado por um grupo de adolescentes, que juntos, compartilham os momentos de aprendizado, de decisões e até de revoltas em que cada um defende seu próprio ponto de vista. Nessa perspectiva, Ballone ${ }^{7}$ trata a adolescência como um período de mudanças físicas e emocionais considerado, por alguns, um momento de conflito ou de crise. Não podemos descrevê-la como simples adaptação às transformações corporais, mas como um importante período no ciclo existencial da pessoa, uma tomada de posição social, familiar, sexual e entre o grupo.

Prosseguindo com nossos achados, tomamos como ponto de partida, uma consulta ao dicionário da língua portuguesa. Ximenes ${ }^{8: 118}$ traz beleza como a "qualidade de belo". Sendo assim, vamos em busca do significado do belo? Diz lá: "de formas agradáveis à visão; bonito, encantador; caráter ou natureza do que é belo".

A partir dessas definições, temos então, uma definição simples, superficial, ou mesmo uma tentativa de traduzir o que acontece na realidade do nosso contexto social. Como nos alerta Porpino: ${ }^{3}$ contentar-se com tais definições seria reduzir nosso conhecimento diante da multiplicidade de significados que podem assumir esses termos. É ainda, aceitar como modelo a seguir, tudo aquilo que nos é mostrado com intuito mercadológico. Então seguiremos com nossas reflexões.

Ao observarmos a história humana, percebemos a diversidade de concepções estéticas atribuídas à beleza em cada cultura e época específicas. Apontamos para a Grécia que retrata um ideal de beleza representada por "Apolo, o deus da medida, da ordem, da proporção, da simetria e do equilíbrio". 3:81

De acordo com Suguihura: ${ }^{9: 199}$

Desde as estátuas gregas, vinculam-se imagens a um discurso que determina o tipo de corpo característico de cada sociedade. Alteram-se valores, padrões, 
medidas e formas de intervenção ao longo do tempo, de acordo com a cultura local, mas há milênios que 'beleza é fundamental'.

Ao longo dos tempos, houve outros olhares, outras concepções de beleza, mas pretendemos aqui enfatizar o ideal apolíneo, já que este se encontra diretamente relacionado à simetria do corpo. E sendo este alvo de aspirações e busca incessante por uma definição que o enquadre nos padrões impostos pela sociedade contemporânea, encontra-se no cerne das preocupações da Educação Física. É por meio da incessante corrida em busca da beleza ideal, ditada pela supremacia da aparência, que os sujeitos, marcados especialmente pela insatisfação com o próprio corpo, procuram construir suas identidades particulares.

Ao admitirmos essa íntima relação do corpo com a beleza, logo nos reportamos para os artifícios utilizados para a manipulação das medidas corporais, o que acarreta uma busca incessante pela perfeição. Esta busca traz à tona a ligação do belo ao feio. Este sendo relacionado à imperfeição, à desordem, e até mesmo, como princípio de preconceitos. A partir daí, os corpos que não seguem tal padrão são vistos como imperfeitos, são apontados; menosprezados. Parece sensacionalismo, drama, mas na verdade configura-se como uma problemática que deve ser discutida e ampliada pelas instituições: a religião, o Estado, a família, e principalmente, a Escola. Precisamos urgentemente de novos discursos que transgridam os já instituídos como verdadeiros.

Durante a pesquisa realizada com alunos do ensino médio, percebemos no primeiro grupo entrevistado - formado pelos alunos da Escola Cooeperativa, da cidade de Parelhas - a presença marcante desse ideal de beleza. Os relatos a seguir retratam a beleza das medidas simétricas e da estreita relação com a perfeição do corpo:

[...] Beleza é o nosso estado físico. Um corpo belo é um corpo sarado (Aluno 3).

[...] Beleza é estar bem fisicamente, porém, tendo que estar bem interiormente. Podendo ser também estar bem consigo mesma. Um corpo belo é aquele bem definido, porém sem exagero, na medida certa para não se tornar feio (Aluno 6).

Essas declarações denotam uma beleza ligada ao corpo físico, sendo este considerado belo pelas suas definições o que o distancia de seu oponente - o feio. Evidenciamos na fala do aluno 6, uma referência à beleza interior. Desse modo, podemos inferir que exista uma visão referente à percepção que vai além do que podemos enxergar. Assim, 
apesar da nítida relação ao corpo físico, já observamos um pensamento um pouco mais abrangente pautado na ideia de que a beleza não se restringe à perfeição dos corpos.

Ainda analisando o primeiro grupo, observamos uma afirmação com relação à beleza ligada às mulheres:

[...] Beleza é uma coisa que todas as mulheres precisam. Um corpo belo é um corpo saudável, que tem um bom preparo físico (Aluno 9).

É muito comum essa associação da beleza com a mulher, exclusivamente. Como vemos nessa declaração, o aluno relata que a beleza é uma necessidade de todas as mulheres. Para constatar tal assertiva, basta sairmos às ruas; adentrarmos nas academias de ginástica; navegar nas redes sociais de relacionamentos; enfim, em todo lugar e a todo o momento nos deparamos com o glamour do corpo feminino. Parece-nos que a mulher passa a ser valorizada a partir de suas curvas. Mas essa associação se sucede não é de hoje; a mulher passou por momentos históricos distintos, onde seu corpo foi exaltado de diferentes maneiras.

Como relata Araújo et al. ${ }^{10}$ No decorrer do tempo, viu-se que a mulher passou a adquirir o controle de seu próprio corpo, principalmente na década de 60, a partir da Revolução Sexual. Nesse momento histórico, apesar de a mulher ter conseguido adquirir sua liberdade com relação a vários aspectos inclusos na sociedade, ainda se notam resquícios de uma submissão, não mais com relação aos ditames do homem, mas, agora, às exigências dessa sociedade com relação a um padrão de uma imagem corporal específica. Apesar da existência de diferentes culturas, podemos afirmar que em todas elas a mulher torna-se objeto de desejo.

A beleza física tão discutida e almejada, muitas vezes acaba sendo vista como um fator primordial para a felicidade das pessoas. A seguir, temos na afirmativa do aluno, essa relação de beleza e felicidade, e ainda uma ligação com o interior das pessoas:

[...] Dependendo da beleza, sendo esta física ou interior, é um ingrediente especial para a felicidade de um indivíduo. Corpo belo é um corpo violão, quando este seja adquirido por malhação em si, não pelo consumo de suplementos ou outros tipos de estimulantes (Aluno 1).

Mais uma vez estamos diante de um conceito que se estende ao interior das pessoas. Já identificamos um ponto positivo por não restringir a beleza à aparência física. Não queremos com isso desviar nossas preocupações com os conceitos restritos que permeia 
nossa sociedade, ao contrário, desejamos usar os discursos de hoje como ponto de partida para possíveis (re)significações da experiência estética na contemporaneidade.

Russo, ${ }^{11}$ em seu artigo "Imagem corporal: construção através da cultura do belo" usa escritos da revista veja, ano 1995, que colabora com os nossos achados: "O fato é que, contemporaneamente a ideia de que para se ter sucesso, felicidade ou dinheiro, o único caminho é através da beleza estética [...]". 11:81

Nas palavras Suguihura:9:199 "Atualmente, as imagens dos ídolos apresentam os modelos de corpos desejáveis, felizes e bem sucedidos, ressaltando-se a beleza física e, normalmente, sem considerar outros pontos da história da vida dessas pessoas".

Vemos, então, a beleza como uma condição para se sobressair na sociedade capitalista na qual nos encontramos, o que gera riscos com relação à saúde e qualidade de vida das pessoas, visto os meios utilizados para se chegar à perfeição do corpo físico, mencionado anteriormente pelos alunos.

Partindo para o segundo grupo pesquisado cuja população é formada pelos alunos do ensino médio do colégio Impacto da cidade de Natal, observamos semelhança com as falas dos alunos do primeiro grupo, como mostra a seguir:

[...] Beleza é aquilo que é belo. Um corpo belo é um corpo definido (Aluno $11)$.

[...] Beleza é um conjunto entre rosto e corpo. Um corpo belo é um rosto bonito e um corpo bonito (Aluno 12).

[...] Beleza são pessoas que chamam atenção. Um corpo belo é um corpo com o físico bonito (Aluno 14).

[...] Beleza é estar bem com o corpo e com a saúde. Um corpo belo é um corpo bem definido (Aluno 16).

Assim, percebemos que esses discursos retomam o ideal apolíneo de beleza, com os corpos ditados pela sociedade através de simetrias padronizadas, definindo-os para que possam ser considerados belos perante todos os olhares. Tudo isso nos leva à preocupação de intervir como profisssionais de Educação Física no ambiente escolar transmitindo novos pensamentos acerca do corpo com diversos sentidos para enxergar o belo. Assim, os desejos de perfeição podem ser desviados para uma ótica de consciência e bem - estar. 
Ainda assim, concordando com Porpino, ${ }^{6}$ não podemos negar que essa concepção clássica nos proporciona cenários estéticos importantes. Entretanto, não devemos nos deter a esse referencial nas aulas de Educação Física, pois representaria uma atitude reduzida, já que prioriza um modelo padrão, negando assim outras interpretações possíveis da beleza.

Nessa perspectiva, surge a importância de buscarmos compreensões de beleza mais abrangentes, com outras interpretações para o belo, sem, no entanto, desprezar o conceito clássico, pois este já tem a importância de se tornar um referencial para se estender aos estudos e pesquisas dentro dessa temática. Para tanto, utilizaremos mais uma vez das palavras de Dufrenne apud Porpino ${ }^{3: 45}$ sobre o belo:

É a qualidade presente em certos objetos - sempre que nos são dados à percepção do ser percebido (mesmo se essa percepção requer longa aprendizagem e longa familiaridade com o objeto). Perfeição do sensível antes de tudo, que se impõe com uma espécie de necessidade e logo desencoraja qualquer idéia de retoque. Mas é também imanência total de um sentido ao sensível, sem o que o objeto seria insignificante: agradável, decorativo ou deleitável quando muito.

Na compreensão do autor, vemos, primeiramente, que a beleza não se restringe ao corpo humano, como observamos nos relatos de alguns alunos dos dois grupos analisados. A beleza se torna um ato de reciprocidade entre o sujeito que percebe e a coisa percebida. Assim, um objeto ou uma situação pode ser belo para mim e não expressar o mesmo para o meu companheiro, do mesmo modo que cada cultura pode considerar os objetos belos de forma distinta ${ }^{3}$.

Ainda na tentativa de decifrar o que viria a ser a beleza, apesar de todas as explicações teóricas, o que não se pode negar é que há uma maneira de o homem se relacionar com o mundo, independentemente, dos ideais de perfeição formal buscados pela produção de imagens. Duarte Júnior apud Pereira ${ }^{12: 4}$ acrescenta:

[...] A beleza, assim como a democracia, a justiça, a liberdade, o amor, etc. é, de certa forma, um conceito 'ideal', um horizonte em direção ao qual caminham os objetos particulares que são 'belos'.

Para esse último autor, assim como para Dufrenne, a beleza habita a relação que um sujeito mantém com um objeto. Mas Duarte apud Pereira ${ }^{12}$ vai além e afirma que nem todos os objetos são capazes de suscitar no homem o sentimento de beleza. Desse modo, reafirmamos o lugar da subjetividade nos nossos discursos. Sendo assim, Conexões: revista da Faculdade de Educação Física da UNICAMP, Campinas, v. 12, n. 3, p. 1-17, jul./set. 2014. 
devemos entender a beleza de acordo com seus momentos históricos e com cada cultura que a trata de maneiras distintas.

A partir da interpretação dos questionários aplicados aos alunos da nossa pesquisa, percebemos um relato que nos chama a atenção ao divergir dos demais quando fala sobre sua concepção de beleza: "Uma coisa que é de grande importância para algumas pessoas, tendo seus diferentes modos de se ver" (Aluno 10).

Com essa afirmação, podemos inferir que a beleza não se restringe ao corpo padronizado como relatam os outros alunos pesquisados. Assim, acreditamos que o aluno em questão, acaba relatando, mesmo que superficialmente, o que os autores citados acima, afirmam sobre a questão da beleza; o que suscita, embora discreto, um avanço nos estudos da nossa pesquisa.

Ressaltamos ainda, na contemporaneidade, a ligação constante que se faz entre saúde e um padrão específico de estética corporal. Mendes ${ }^{14}$ afirma que essa relação entre saúde e estética não é algo recente, pois se revelam rupturas e continuidades. Conforme afirmam os sujeitos ao serem indagados sobre o que entendem por beleza e como definiriam um corpo belo, destacam-se as seguintes falas:

\footnotetext{
[...] "Beleza é estar bem com o corpo e a saúde" (Aluno 16).

[...] Um corpo belo é "um corpo saudável de uma pessoa não muito magra, mas também não gorda" (Aluno 18).

[...] "Uma pessoa bonita... E que esta pessoa esteja saudável". Um corpo belo é "um corpo saudável" (Aluno 19).
}

Se analisarmos o processo histórico da Educação Física no Brasil, perceberemos que essa legitimação da saúde com as práticas corporais é bastante antiga. Os estudos de Mendes ${ }^{13}$ na análise da produção do conhecimento da Revista Brasileira de Ciências do Esporte apontam para o conceito de saúde que, do ideal de robustez preconizado no final do século XIX e início do XX, passa a ser relacionado com a boa forma. Dessa forma, o conceito de saúde passa a se entrelaçar com o conceito de estética compreendida como um padrão único de beleza.

Atualmente, no ambiente escolar, ainda é muito comum essa relação da beleza com a saúde. Os alunos passam a adquirir um estilo de vida que envolva práticas corporais com intuitos estéticos e a saúde do corpo. "Desse modo, destacamos que a Educação 
Física poderá ampliar a relação entre saúde e estética a partir de um corpo idealizado, atrelando-se a uma estética da vida bela, atenta às necessidades e desejos de cada corpo e de quem convive conosco na sociedade". ${ }^{14: 5}$

Ao observamos os discursos dos alunos, uma delas nos traz a satisfação ao vê-la como questionamento do próprio aluno portando-se como ser crítico. Ao indagarmos sobre o que o aluno entende por beleza, obtivemos como resposta:

[...] "Não sei se beleza é realmente os padrões que a sociedade de hoje determina (magreza)" (Aluno 18).

A importância dessa declaração se traduz no fato de o aluno já questionar a padronização de beleza imposta pela sociedade, possivelmente não tomando como verdade essa idealização de corpo belo que vemos tão acentuada na contemporaneidade. A Educação Física precisa aproveitar o ambiente escolar para incitar discussões sobre as problemáticas que abarcam nossa sociedade, permitindo que os alunos relatem suas inquietações perante o mundo vivido.

Feitas tais reflexões, percebemos que os dois grupos pesquisados, apesar de pertencerem a escolas de cidades distintas, e possivelmente, enquadrados já em uma cultura um pouco diferenciada, apresentam uma visão unidirecional que atentam para uma beleza fundada na aparência. Entretanto, houve algumas exceções que foram citadas e "exaltadas"; primeiro, por se tratar de opiniões que se distanciaram dessa linha de pensamento dos demais, e segundo, por servirem como subsídios para possíveis discussões acerca da temática aqui discutida.

\section{O VAlOR DA ESTÉtica NO TRATO PEDAgógico DA EDUCAÇÃO FÍSICA: DISCUSSÕES FINAIS}

Os discursos sobre a estética da beleza estão se tornando cada vez mais homogêneos. Observamos durante nossa pesquisa uma concepção de beleza centrada na aparência de um corpo baseado em proporções, medidas, curvas definidas, enfim, um corpo camuflado pelos modelos ditados pela sociedade. Hoje, tudo parece fazer parte das interpretações subjetivas da aparência do outro. 
Assim, em nossa sociedade contemporânea reina a herança dualista; fala-se da liberação do corpo e esquecem que a condição humana é corporal. Parece-nos que ter um corpo impera o "ser corpo". ${ }^{15}$ Dentro desse contexto, a estética se encontra imbricada aos sentidos da visão em detrimento dos demais sentidos, onde a aparência define o ser.

É caminhando de encontro aos ideais de beleza implícitos nesta sociedade que pretendemos tratar a estética no trato pedagógico da Educação Física. Os Parâmetros Curriculares Nacionais ${ }^{1}$ trazem os conteúdos dessa disciplina divididos em três blocos: em um bloco estão os esportes, jogos, lutas e ginásticas, outro bloco é constituído pelas atividades rítmicas e expressivas e o terceiro bloco traz os conhecimentos sobre o corpo. Tal divisão facilita o processo de ensino do professor, além de trabalhar uma concepção mais abrangente que contemple todas as dimensões envolvidas em cada prática corporal, mudando assim, a ênfase na aptidão física e no rendimento padronizado que caracteriza a Educação Física.

Trata-se, então, de localizar em cada uma dessas manifestações (jogo, esporte, dança, ginástica e luta) seus benefícios fisiológicos e psicológicos e suas possibilidades de utilização como instrumentos de comunicação, expressão, lazer e cultura, e formular a partir daí as propostas para a Educação Física escolar. ${ }^{1: 27}$

Nesse âmbito, visualizamos um meio de atenuar várias problemáticas que surgem no cotidiano das pessoas. E principalmente, as questões sobre a beleza relacionada aos corpos. Podemos partir dos próprios conceitos que os alunos possuem referenciados por esse padrão aqui discutido. Em seguida, validamos uma construção de novos conceitos construídos de maneira conjunta com professores e alunos, e assim, apontar para novos olhares que abarquem o universo da experiência estética.

E como nos mostra Medeiros, ${ }^{16}$ esta experiência estética não surge apenas no corpo, nem é uma qualidade somente inerente aos objetos, mas sim no entrelaçamento de meu corpo com determinadas qualidades presentes nos objetos que têm a capacidade de arrebatar, que aguçam os sentidos. Desse modo, vislumbramos nos conteúdos da Educação Física escolar uma oportunidade de vivenciar tal experiência, como na dança, de modo como sugere Porpino ${ }^{3: 138}$.

[...] A dança pode ser compreendida como educação capaz de permitir e despertar um sentido de beleza, que não se prende a padrões ou a dicotomias, mas que rejunta fragmentos e abre novos horizontes para uma vida que não negue a sua própria realidade paradoxal. 
A dança, nessa perspectiva, torna-se um instrumento de ensino para incitarmos discussões acerca do tema aqui abordado, assim como, propicia a própria vivência estética. Ela é capaz de aguçar todos os nossos sentidos, o que elimina o ar nobre da visão, tão valorizada na apreciação do corpo belo.

A partir dessas considerações, acreditamos que os discursos da beleza e do corpo devem traduzir-se como uma preocupação educativa. Conforme Mendes, ${ }^{13}$ o corpo como condição existencial, como é tratado nas obras de Merleau-Ponty, já está presente na educação. Portanto, temos o desafio de superar os dualismos e as práticas disciplinares que o atravessam.

Devemos contemplar, portanto, uma educação que atente para as políticas assistencialistas; para os ideais estipulados pela nossa sociedade capitalista. Uma educação que contemple as aventuras pessoais, os acontecimentos banais, ou históricos, a linguagem do corpo. ${ }^{13}$ Enfim, uma educação que excite a todos e desperte a sensibilidade.

Precisamos exercitar nosso modo de reaprender a ver o mundo. E é através das nossas experiências vividas que mergulhamos na complexidade do mundo. Avancemos! E juntos, continuemos refletindo sobre as questões emergentes de uma sociedade paradoxal: que avança e ao mesmo tempo retrocede em seus conceitos.

\section{REFERÊNCIAS}

${ }^{1}$ BRASIL. Ministério da Educação e Cultura. Parâmetros curriculares nacionais: educação física. Brasília, 1997.

${ }^{2}$ NÓBREGA, T. P. Corporeidade e educação física do corpo-objeto ao corposujeito. 2. ed. Natal: Ed. da UFRN, 2005.

${ }^{3}$ PORPINO, K. de O. Dança é educação: interfaces entre corporeidade e estética. Natal, RN: EDUFRN - Ed. da UFRN, 2006.

${ }^{4}$ PARISOLI, M. M. M. Pensar o corpo. Petrópolis, Vozes, 2004. 
${ }^{5}$ TOLLEDO, M. Nietzcshe e a distinção entre apolíneo e Dionisíaco. Revista Filosofia Capital, Brasília, v. 2, n. 4, ano 2007. Disponível em: <www.filosofiacapital.org/ojs2.1.1/index.php/filosofiacapital/article/viewFile/45/38>. Acesso em: 15 nov. 2011.

${ }^{6}$ PORPINO, K. O. Interfaces entre corpo e estética: (re)desenhando paisagens epistemológicas e pedagógicas na Educação Física. In: LUCENA, R.; SOUZA, E. (Org.). Educação Física, esporte e sociedade. João Pessoa: Ed. da UFPB, 2003. p. 145-160.

${ }^{7}$ BALlONE, G. J. Gravidez na adolescência. São Paulo, 2003. Disponível em: <http://gballone.sites.uol.com.br/infantil/adolesc3.html>. Acesso em: 10 jun. 2010.

${ }^{8}$ XIMENES, S. Dicionário da língua portuguesa. São Paulo: Ediouro, 2011.

${ }^{9}$ SUGUIHURA, F. M. Mito e beleza: a estatuária grega na revista Educação Physica. Pro-Posições, Campinas, v. 18, n. 1 jan./abr. 2007. Disponível em: <TTP://74.125.155.132/scholar?q=cache:M3CN3QxnpyoJ:scholar.google.com/+Suguih ura+(2007)\&hl=pt-BR\&lr=lang_pt\&as_sdt=2000>. Acesso em: 25 mar. 2010.

${ }^{10}$ ARAÚJO, D. C.; BALDISSERA. R.; STOFFEL, A. Modelos femininos comercializados por anúncios publicitários na mídia eletrônica. Disponível em: <http://www.intercom.org.br/papers/outros/hmidia2007/resumos/R0113-1.pdf>. Acesso em: 17 mar. 2010.

${ }^{11}$ RUSSO, R. Imagem corporal: construção através da cultura do belo. Movimento \& Percepção, Espírito Santo de Pinhal, v. 5, n. 6, jan./jun. 2005. Disponível em: <TTP://www.mestreclaudio.pro.br/up/arquivos/Imagem\%20corporal.pdf>. Acesso em: 19 maio 2010 .

${ }^{12}$ PEREIRA, V. Estética e imagem: onde reside a beleza? Disponível em: $<$ http://paginas.unisul.br/agcom/revistacientifica/artigos_2008b/valdezia_pereira.pdf>. Acesso em: 19 maio 2010 
${ }^{13}$ MENDES, M. I. B. S. Mens sana in corpore sano: saberes e práticas educativas sobre sorpo e saúde. Porto Alegre: Sulina, 2007.

14

A saúde e a estética da vida bela. Disponível em:

<http://www.cbce.org.br/cd/resumos/002.pdf>. Acesso em: 19 mar. 2010.

${ }^{15}$ LE BRETON, D. Antropologia do corpo e modernidade. Petrópolis: Vozes, 2011.

${ }^{16}$ MEDEIROS, R. M. N. Uma educação tecida no corpo. São Paulo: Annablume, 2010 .

Recebido em: 15 fev. 2014

Aceito em: 29 set. 2014

Contato: rayanenobrega@yahoo.com.br 